\title{
ESPACIO, CUERPO-SUJETO, TECNOLOGÍA. LA CONSTRUCCIÓN DEL MITO DE LA HISTORIA DE CHILE EN LA OBRA DE JORGE BARADIT
}

\author{
Space, Body-Subject, Technology. The Construction of the Myth of Chile's \\ History in the Work of Jorge Baradit
}

\section{RESUMEN}

En este artículo se propone que la obra de Jorge Baradit es un dispositivo que procesa fragmentos de sujeto-cuerpo, espacio y tecnología para construir el mito de la historia de Chile. En su operación, esta máquina convierte el país en cuerpo y el cuerpo en espacio, y los usa como piezas que conforman tecnologías violentas de dominación que esclavizan a los sujetos poniéndolos al servicio de poderes desconocidos en función de intereses superiores y malignos, en una concepción en que el tiempo es maleable y las palabras son mágicas pues inciden en lo real. De este modo se va construyendo una "historia secreta" en la que se relatan, entre otros episodios, la conquista de América, el golpe de estado de 1973 y la dictadura de Pinochet, historia mítica que participa en la creación del imaginario social del capitalismo tardío como se configura hoy en Latinoamérica.

Palabras claves: Imaginario social; cuerposujeto; espacio; tecnología.

\section{UNIVERSUM}

Revista de Humanidades y Ciencias Sociales

\author{
MACARENA ARECO \\ Doctora en Literatura, \\ Centro de Estudios de Literatura \\ Chilena, CELICH Pontifica \\ Universidad Católica de Chile. \\ Correo electrónico: \\ mareco@uc.cl \\ ORCID: 0000-0003-3266-1156 \\ ResearchGate: \\ Scholar.google: \\ Academia.edu:
}

Este artículo fue escrito en el marco del proyecto Fondecyt Regular $\mathrm{N}^{\mathrm{o}}$ 1171124 "Imaginarios sociales en la ciencia ficción latinoamericana reciente: espacio, sujeto-cuerpo y tecnología". Antes, fue presentado en el congreso Mitos Prehispánicos y Mitos Clásicos en la Literatura Latinoamericana, realizado en la Universidad de la Sapienza, Roma, entre el 20 y el 22 de septiembre de 2017.

Artículo recibido el 26 de abril, 2019. Aceptado el 24 de marzo, 2020.

DOI:

Web: http://universum.utalca.cl | ISSN: 0716-498X - 0718-2376 


\begin{abstract}
In this paper, it is proposed that Jorge Baradit's work is a device that processes fragments of subject-body, space and technology to construct the myth of the history of Chile. In its operation, this machine turns the country into a body and the body into space, and uses them as pieces that make up violent technologies of domination that enslave subjects, putting them at the service of unknown powers based on superior and evil interests. Here, the notion of time is malleable, and words are magical because they affect the real. In this way, a "secret history" is being built in which, among other episodes, the conquest of America, the coup d'état of 1973 and the Pinochet dictatorship are recounted, a mythical history that participates in the creation of the social imaginary of late capitalism as it is configured today in Latin America.
\end{abstract}

Keywords: Social imaginary; subject-body; space; technology.

La obra del escritor chileno Jorge Baradit (1969) —a la fecha compuesta por las novelas Ygdrasil (2005), Synco (2008), Kalfukura (2009) y Lluscuma (2013), además de la nouvelle Trinidad (2007), la novela gráfica Policía del Karma (2011), el libro de cuentos La guerra interior (2017) y los volúmenes de ensayos la Historia secreta de Chile I, II y III (2015, 2016, 2017, respectivamente), La dictadura (2018), Rebelión (2019) y Héroes (2019)— prolifera como un rizoma, es decir como una multiplicidad heterogénea en la que se interconectan, despliegan y repliegan, confluyen y dimanan, fragmentos de los más diversos códigos — mitos, historia, subgéneros de la ciencia ficción, obras visuales_- lo que a veces la vuelve, al menos en el ámbito ficcional, de difícil acceso, opaca, no obstante la evidente vocación popular que el autor ha desplegado sobre todo en sus textos de divulgación histórica, que ocupan desde hace ya varios años los primeros lugares en las listas de libros más vendidos en el país.

Como una propuesta de inteligibilidad, en este trabajo desarrollo un acercamiento a través de tres fragmentos temáticos que tienen una presencia 
fundamental en sus relatos: espacio, cuerpo-sujeto ${ }^{1}$ y tecnología. $\mathrm{Al}$ respecto propongo que estos elementos forman parte de una máquina ${ }^{2}$ que genera como producto el mito de la Historia de Chile (y secundariamente también de América), entendido como un relato sobre los orígenes del continente cuyo centro es la nación transcordillerana, a través del cual se intenta dar respuesta a una problemática que obsesiona al autor: ¿cómo opera la esclavización de los sujetos, aparentemente sin retorno, en la periferia del capitalismo tardío? ${ }^{3}$

En el marco de la investigación en que se enmarca este trabajo, el mito creado por Baradit contribuye a la formación del imaginario social, definido por Cornelius Castoriadis como "[c]reación incesante, indeterminada y colectiva de imágenes (figuras, formas) que produce realidad" (12). A partir de este concepto, Bronislaw Baczko desarrolla la siguiente explicación:

[a] lo largo de toda la historia las sociedades se entregan a un trabajo permanente de invención de sus propias representaciones globales como ideas-imágenes por medio de las cuales se dan una identidad, perciben sus divisiones, legitiman su poder, elaboran modelos formativos para sus miembros (8).

1 Lo escribo de esta manera para dar cuenta de lo que, según David Le Breton, es el imaginario del cuerpo en la modernidad, una materialidad completamente separada del yo, que es concebido como "un accesorio de la persona [que] se desliza hacia el registro del poseer" o "una maquinaria corporal reductible solo a una extensión" (1990 69). En otros trabajos desarrollados en el recién mencionado proyecto de investigación, todavía inéditos, exploro con detalle está cuestión.

2 Uso en este artículo las palabras dispositivo y máquina como sinónimos, en el sentido básico de aparato, formado por piezas e impulsado por algún tipo de energía, que genera un producto, lo cual se corresponde con las definiciones que entrega la RAE: "3. m. Mecanismo o artificio para producir una acción prevista" y " 2 . f. Conjunto de aparatos combinados para recibir cierta forma de energía y transformarla en otra más adecuada, o para producir un efecto determinado. / 3. f. Agregado de diversas partes ordenadas entre sí y dirigidas a la formación de un todo". Más complejamente, con "máquina" intento marcar, y en ello sigo a Deleuze y Guattari, el carácter no solamente reproductor, sino creador de la obra de Baradit (su carácter de "fábrica", no de "teatro", como dirían los filósofos franceses), en el sentido de la tesis de este ensayo de que esta produce un mito de la Historia de Chile. Se trataría, así de una máquina del tipo "máquinas abstractas de consistencia, singulares y mutantes, de conexiones multiplicadas", la cual conectaría territorio, sujeto-cuerpo y tecnología; una máquina que, en la eventualidad de la mistificación del mito, podría transformarse en una del tipo "abstractas sobrecodificantes o axiomatizantes, que realizan las totalizaciones, las homogeneizaciones, las conjunciones de cierre" (Mil mesetas 522).

3 Para la noción de mito como una narración que intenta resolver un problema, ver Gilbert y Gubar 265. 
A esto Josefina Ludmer le llama "imaginación pública o fábrica de la realidad" (11). Considerando estas visiones, el imaginario social se concibe como un espacio de disputa, en el cual se van modificando las figuraciones que una comunidad tiene sobre su experiencia presente, sobre su historia y su futuro, a partir de diversas intervenciones, entre ellas, como ocurre en este caso, la de la literatura.

\section{EL DISPOSITIVO}

Los tres elementos ya mencionados - espacio, cuerpo-sujeto, tecnología - constituyen un triángulo en movimiento, una especie de máquina procesadora, con motor y cuchillos, que va cortando, incorporando, mezclando y dando forma a materiales diversos según formatos también dispares. Algunas materias primas son: mitos precolombinos, hindúes y nórdicos, historia chilena, latinoamericana y europea, gnosticismo, esoteria y sicodelia. Por ejemplo, el árbol de la vida, la mezcalina y el imbunche en Ygdrasil; la serpiente Cai Cai y la kundalini, la guerra del Pacífico y la abducción del cabo Valdés en Lluscuma; el golpe de Estado de Pinochet y la mitología nazi ocultista de Miguel Serrano en Synco. Algunos formatos: el ciberpunk, el splatter punk, el muralismo mexicano, el accionismo vienés y el poshumanismo de Sterlac en Ygrasdil; el steampunk o retrofuturismo, el relato negro y la ucronía en Synco; el comic en Policía del Karma; el ensayo de divulgación en la Historia secreta y en general las ilustraciones presentes en todos sus libros, algunas creadas por el propio autor y otras por artistas como Martín Cáceres. ${ }^{4}$

Un proceso en permanente traslación, que se desplaza en un plano espacio-temporal, sobre una línea horizontal que es el territorio de Chile, tomandoy dejando, digiriendoy expulsando desde el pasado, metamorfoseando, a partir de lo cual el aparato va construyendo el mito de la historia con los tres componentes ya mencionados: espacio, cuerpo-sujeto y tecnología.

4 Analizo estas hibridizaciones en el artículo que incluyo en la bibliografía. 


\section{ESPACIO}

El soporte fundamental sobre el cual el dispositivo opera es la larga y angosta faja de tierra que constituye el territorio chileno, desde el desierto de Atacama en el Norte, hasta la Patagonia en el Sur, pasando por Santiago, Valparaíso y otros lugares significativos como el Wallmapu, el territorio mapuche. A veces ese espacio se contextualiza en el continente americano, como ocurre, entre otros, en "La conquista mágica de América" que revisaremos más adelante, pero el centro es la nación, lo que se muestra, por ejemplo, en Lluscuma ${ }^{5}$. Según se relata en este texto, en Chile se desarrolla una guerra oculta, que lo está partiendo en sus cuatro puntos cardinales:

Mi mente está quebrada, el país está rompiéndose en cuatro pedazos.

En el norte se levantaron los obreros del cobre y desde Chuquicamata amenazan con avanzar sobre Santiago con pelotones de fantasmas de soldados de la Guerra del Pacífico y anarquistas fusilados que volvieron de los paredones [...].

Desde el sur se levantaron los otros, los que se sienten astronautas a caballo colonizando otro planeta en la estepa patagona [...].

Desde el oeste los brujos chilotes se desenterraron y miran en secreto hacia el continente pero ya no más [...].

Hacia el este se reúnen los konas de la Wallmapu [... (203-204). ${ }^{6}$

Esta descripción del espacio imbuida por la cosmovisión mapuche ${ }^{7}$ se hibridiza con el hinduismo, a través de la figura de la serpiente Kundalini,

5 En la novela se percibe la obsesión por Chile, de lo cual solo es una muestra el que la palabra aparezca unas ochenta veces. Por otra parte, según se cuenta en "La conquista mágica de América", el fin último de esta operación es hacerse de la piedra azul caída de la diadema de Lucifer que se encuentra dentro de la cabeza de una machi del sur de Chile.

6 Las rebeliones cardinales tienen su elemento y su color: "El norte y sus obreros socialistas, fuego rojo; el sur con sus colonos fascistas, aire azul. / El oeste y su nostalgia por España, agua negra; el este y su deuda ancestral clavada bajo tierra kilómetros hasta el fondo de su recuerdo, el alba antes de que salga el Sol, el blanco de Ngenechén" (204).

7 En su diccionario de mitos Sonia Montecino explica que, según algunas fuentes, el cosmos concebido por los mapuche está formado por tres espacios: el Wenumapu, mundo de arriba de los espíritus; el Nag Mapu, espacio intermedio de los seres vivos, y el Minche Mapu, espacio negativo donde habitan los malos espíritus, pero también los ngen. Agrega que este universo contiene otra dimensión, el Wall Mapu, "que se relaciona con los cuatro puntos cardinales" (446). "[L]os ngen son los dueños o espíritus de todas las cosas de la naturaleza, las que habitan en su interior y a su vez las cuidan" (325). 
según lo cual el territorio nacional se imagina como una culebra por la que se desplaza la energía de la guerra secreta:

Chile es una serpiente enterrada como una semilla [...]. A veces sueño con ella. A veces está enterrada en mi propio cuerpo y tiene la forma de mi columna vertebral. Entonces la veo saltar desde la Patagonia, abrir la boca cerca del lago Chungará, cerca de Arica, y morderme el cráneo con tanto placer que mancho la cama (13).

Como vemos, la máquina baraditiana sintetiza espacio y sujeto en una relación pulsional, de deseo, en que los límites se borran, lo que hace que el joven narrador protagonista de Lluscuma, Fernando Camargo, identifique su cuerpo, mimetizado con una serpiente, con el territorio: ${ }^{8}$

Soy la S que repta de norte a sur. Chile salió arrastrándose desde el lago Chungará, remojado en placenta, y se desmoronó hacia abajo por el mapa desenrollando su brazo, el dedo, tratando de alcanzar la Antártica, la serpiente de piedra que se rompe la cabeza en mil pedazos y fiordos al final, y no llega jamás. La forma de una flecha apuntando a la tierra incógnita, la forma de la cicatriz en el cráneo del planeta por donde se fuga la energía tectónica, los demonios y los terremotos (201).

La cicatriz hace referencia al estigma que porta el personaje en su cabeza, producto de una golpiza que le dio su padre militar, la cual también hace que su cuerpo se confunda con el territorio nacional, pues la marca es similar al mapa del país: "Mi tata decía que [mi cicatriz] tenía la forma de Chile, que yo era un patriota" (13). Pero también está la herida que significa haberse dado cuenta de que su abuelo, quien lo crió y a quien quiso, fue un violador de los derechos humanos.

\section{CUERPO-SUJETO}

El dispositivo que Baradit pone en funcionamiento reincide en describir cuerpos marcados, heridos, mutilados, descuartizados y crucificados que se constituyen como partes de mecanismos construidos con fines más y

8 Es, en este sentido, una máquina deseante "En las máquinas deseantes todo funciona al mismo tiempo, pero en los hiatos y las rupturas, las averías y los fallos, las intermitencias y los cortocircuitos, las distancias y las fragmentaciones, en una suma que jamás reúne sus partes en un todo" (Anti-Edipo 50). De ahí que en el siguiente apartado se planteará que Fernando es un sujeto fallado, roto, pues las máquinas deseantes "solo funcionan descompuestas" (38-39). 
más oscuros. Así por ejemplo, en Ygdrasil, los pensantes: "fetos poltergeist trasladados a úteros de yeguas, donde tienen espacio para crecer mientras dura su vida útil de tres años. Las yeguas tienen las patas amputadas y cuelgan de los techos de enormes hangares en hileras interminables" (210); o la subcarpeta "Prototipos":

Estaba repleta de mecanismos y aparatos que incluían humanos vivos insertos en sus formas, los que compartían sus funciones neurobiológicas y eran penetrados por organismos electrónicos a través de ojos, oídos y columna vertebral. Niños y mujeres preñadas clavados a maquinarias [...] para extraerles sus principios astrales o estimular la emisión de energía en forma de miedo o dolor (120).

Se trata del cuerpo entendido como carne, es decir, como insumo o parte de mecanismos que buscan el cumplimiento de objetivos superiores, los que van variando de relato en relato pero siempre se relacionan con la apertura de puertas que, como ocurre en las historias de Lovecraft, permitirán el acceso de espíritus malignos a nuestro espacio/tiempo. En estos casos nunca contamos con personajes determinados, solo con cuerpos o partes que son conectados unos con otros para cumplir fines siniestros. Pero también hay sujetos, con nombre y biografía, en los que se delínea una individualidad marcada por una historia personal traumática. Es el caso ya mencionado de Fernando Camargo y también el de Mariana, la protagonista de Ygdrasil, quien fue abusada por su padre en la infancia y se ha convertido en una sicaria adicta. Son personajes dañados, quebrados, que imaginan una agencia ilusoria, pues finalmente siempre devienen cuerpos, es decir, materia prima esclava, utilizada más allá de su voluntad por otros.

Así a Camargo se lo describe como un sujeto doliente y roto:

La hormiga vuelve a morderme el mismo nervio, un color congelado rasga la atmósfera y rebota en la Luna con un golpe de gong que me parte el cráneo. Un dolor de muelas de la mente, digo, y el Mako se caga de la risa y me dice que soy un juguete quebrado, pero que me quiere igual. Soy un contador geiger quebrado [...]. Soy una máquina fotográfica que capta muertos (46). 
Esta subjetividad rota hace posible su utilización como objeto: "Siempre me duele la cabeza. Deben estar usándola para transmitir los códigos de algo" (13). Así, el sujeto-cuerpo quebrado, doliente, finalmente termina constituyéndose en un aparato tecnológico empleado por otros para cumplir fines desconocidos. ${ }^{9}$

\section{TECNOLOGÍA}

Hemos mostrado cómo, en la máquina que opera en la obra de Baradit, el espacio se animaliza y el cuerpo se mimetiza con el territorio, al tiempo que, visto como carne, es fragmentado y conectado en pos de proyectos siniestros. En estas mezclas y yuxtaposiciones los espacios y los cuerpos devienen tecnologías.

Así, como se relata en "La conquista mágica de América", las iglesias construidas sobre templos indígenas son maquinarias de dominio: "siempre se construía una iglesia encima, como llave ritual obstruyendo la respiración del territorio" (17). En la misma línea, en el presente, el templo del consumo, la torre Costanera Center, la más alta del país, donde se ubica un enorme centro comercial, también es un dispositivo espacial tecnológico: "la imagino como uno de los clavos monstruosos que mantienen fijo el cuero de la pachamama al mapa geopolítico del país" (Lluscuma 16).

El territorio nacional, en su totalidad, es asimismo descrito como una maquinaria, formada por fragmentos de espacio y de cuerpo. En este marco, el lago Chungará, en cuyo fondo ha sido hundida la catedral de Colonia, se define como:

9 Está visión no coincide con la propuesta por Haraway, para quien la subjetividad intervenida por la tecnología es una posibilidad de emancipación: "Estoy argumentando en favor del cyborg como una ficción que abarca nuestra realidad social y corporal y como un recurso imaginativo sugerente de acoplamientos muy fructíferos" (254). Coincide, en cambio, con lo planteado por Andrew Brown en Cyborgs en Latina America, según el cual lo que aparece en novelas latinoamericanas de las últimas décadas es "the power of these figures to enunciate contemporary realities, be they those traumatized realities of the postdictatorship [y dictadura, habría que agregar en el caso de Lluscuma], be they the everyday lives of individuals surrounded by effects of neoliberal policy" (176). 
[...] el sistema límbico desde donde le fabricarán un sistema nervioso al país con personas enterradas, personas cosidas a otras personas, compartiendo uretras, órganos; un hígado para tres cuerpos cosidos con alambres por el esternón, sin piernas, conectados, aglomeraciones de cuerpos corcheteados, atornillados por el hueso entrando uno en el otro, ganglios gigantes bajo tierra comunicados con ligamento y nervio a otros ganglios hechos con desaparecidos enterrados, funcionando como neuronas cada doscientos metros a lo largo de este país cyborg. Porque estamos fabricando un país cyborg (214).

Sujeto y territorio, carne y nación son partes que constituyen máquinas de guerra, inconscientes, que no saben a qué poderes están sirviendo, al mismo tiempo que máquinas quebradas, viejas y obsoletas. Así, si se analizan las descripciones tecnológicas en la obra de Baradit, lo que prima es una tecnología caída, sin aura, que solo ha tenido sentido como instrumento de dominación.

La tecnología degradada se puede observar, por ejemplo, en la caracterización de Fernando como antena: "Me siento un astronauta en este planeta usando tecnología de muy mala calidad, mirando una reconstrucción de bajísima resolución, un modelado barato mal rendereado" (23). Valdés, el cabo que protagonizó el episodio Lluscuma, describe su identidad borrosa por medio de un formato de grabación obsoleto:

¿cómo explicarles que hay momentos del día en que me veo borroso, con mala definición, como la copia de la copia de un VHS pirata? Mi familia ya no es mi familia, no tengo derecho a ella, soy una sombra de mala calidad (90).

Y Camargo también se sirve de la tecnología defectuosa para expresar su sensación de sí mismo: "Me siento un televisor en mal estado con la carta de ajuste chueca y el pitido de fin de transmisiones" (105).

Un caso particularmente esperpéntico de tecnología anticuada en vínculo con el cuerpo, es el del joven senador socialista Carlos Altamirano, líder de la oposicón a la falsa realidad del Chile del 78, quien en los últimos días de la Unidad Popular fue acusado de sedición — esto es histórico- y en noviembre del 73 sobrevivió a la "Matanza de los Santos Inocentes" —esto es ficción-en precarias condiciones físicas: 
Un hombre que tiene su corazón fuera del cuerpo, mantenido en una cámara presurizada y con la mitad de su sistema digestivo reemplazado por bolsas plásticas, cosidas a las paredes interiores de su abdómen, rellenas de tierra de cultivo, parásitos y pequeños animales que reducen los alimentos [...]. Alguien que tiene su sistema nefrológico paralizado y que debe usar cerdos vivos amarrados bajo su cama para filtrar su sangre [...]. (59) ${ }^{10}$

En la coordinación de los rebeldes la tecnología es también anticuada. Así Altamirano se conecta a través de

carros, que recibían y enviaban la imagen de lo que ocurría al panel instalado sobre el cielo raso de la habitación del mutilado. Los rusos llamaban 'Kontrol' a ese prototipo, un constructo caótico de pantallas y tubos al vacío, radios de onda corta, transmisores y micrófonos radiales que bajaban con elásticos y poleas hasta el nivel de la cama de hospital (151).

\section{LA CREACIÓN DEL MITO DE LA HISTORIA DE CHILE}

La máquina que recorre el tiempo-espacio, cortando y pegando fragmentos de sujetos-cuerpos y conformando tecnología, va construyendo el mito de la "historia secreta" de Chile, el cual se inicia con la conquista mágica de América, tal como se explica en el primer relato de La guerra interior. Para ser precisos, es el año 1227 y un cabalista sevillano logra, después de arduos cálculos, descubrir la fecha exacta en que debe producirse la invasión de América, territorio de gran energía cósmica, del cual los europeos vienen

10 Otro caso de sujetos descritos como máquina es la del Grupo de Amigos del Presidente, cuyo referente es el grupo histórico de jóvenes miristas a cargo de la seguridad de Allende, el cual es representado en la novela con elementos de esoterismo hinduista y mariano: "A Martina se le encoge el corazón al ver que en la calle se arma con antorchas el signo de la doble flecha de los GAP [...]. La banda avanza tocando una pieza plagada de sonidos guturales, casi fúnebre, lejanamente similar a los sonidos de trompas de los lamas tibetanos, y se encajona en un costado para darle paso a un escuadrón de GAP, que avanzan silenciosamente con su paso contenido, maquinal. Vestidos de riguroso café, como la virgen del Carmen, patrona de Chile, caminan armados con guantes blancos sosteniendo en ristre sus AK-47. Corbata negra, todo el vello del cuerpo rapado y lentes oscuros que se sacan al pasar frente al estrado para ejecutar su famoso 'paso del peregrino', su característico desfile con los ojos completamente cerrados, como símbolo de su compromiso con la vida interior. Ellos dicen 'mirar hacia adentro' y el mito urbano dice que en realidad se sacan los ojos cuando son admitidos en el cuerpo. La gente los respeta, los admira y les teme. Son sobrehumanos" (207). 
teniendo noticias desde hace un par de siglos, pues los mediums han percibido la presencia de nuevas conciencias en el plano astral. La conquista se prepara hasta en sus mínimos detalles. Primero se crea un aparato formado por muertos en cuya descripción se mezclan los inicios de la radiotelefonía y la esoteria, con algo de la reminiscencia proustiana:

De inmediato un selecto equipo de videntes fue asesinado y enterrado en una línea recta apuntando hacia las nuevas señales. Todos eran de signo Géminis, todos cargaban una roca de cobre en el estómago. Los médiums comenzaron a recibir las transmisiones de los videntes asesinados, haciendo puente casi de inmediato. Las señales eran difusas y afloraban como débiles imágenes en blanco y negro, adhiriéndose llenas de estática a las retinas de los médiums como recuerdos de infancia: un olor desconocido, el multicolor del manto de una madre, la certeza en la existencia del Tamoanchán. (14)

A continuación, se ponen en práctica técnicas de dominacion mágicas. La primera de ellas es nombrar:

Cuando Cortés desembarcó, subió a su caballo y un representante le indicó el nombre con que debía nombrar el lugar para hacerlo seguro. Le recomendó nunca desmontar antes de renombrar los lugares. De ahí en adelante cada sitio conquistado era rápidamente renombrado con un 'conjuro-llave', codificado tras un nombre cristiano, que anulaba la energía opositora y encarcelaba entre las letras al numen protector del lugar. De esa manera avanzaban con seguridad por terrenos incapaces de defenderse. (17)

Luego, el siguiente paso, es eliminar los lugares protectores y sellar los centros vitales: "Cada templo mayor era desmantelado cuidadosamente para exponer el 'punto blando' y cegarlo con cantos y signos de oscuridad. Siempre se construía una iglesia encima, como llave ritual obstruyendo la respiración del territorio" (17). Se van así destruyendo los puntos enérgeticos de América: "los representantes [de las logias oscuras] guiaban a los capitanes en el primer objetivo: bajar a través de la cordillera de los Andes destruyendo uno por uno los chakras de América para debilitarla” (17). Se clavan, además, por todo el continente, infinitas cruces, "siguiendo un exacto diagrama de aucupuntura negra para debilitar la tierra y mantenerla adormecida" (22) ."El rito de conquista avanzaba como una infección"(17); la Tierra es un cuerpo que se va enfermando. 
En este episodio la máquina creadora de mitos se muestra en todos sus componentes: el espacio latinoamericano entendido como un cuerpo, en el cual se distribuyen centros de energía que, según la visión del hinduismo, es posible abrir o cerrar; los sujetos conformando maquinarias de tecnología anticuada al servicio de la dominación; la historia del expansionismo europeocatólico como un ritual mágico al mismo tiempo que como una contaminación del territorio-cuerpo produciendo la dominación y la esclavitud.

El mito de la Historia de Chile incluye una historia oculta de la República, que es relatada en Lluscuma, la cual esconde el secreto de la guerra permanente. De acuerdo con este, en el país existiría una conflagración desde mediados del siglo XIX, iniciada por los ingleses contra los españoles, para apoderarse del desierto de Atacama — que es en realidad un pedazo de otro planeta-, crear en el lago Chungará un cerebro, construir una antena y permitir a almas oscuras cruzar desde el más allá. La Guerra del Pacífico, el suicidio de los presidentes Balmaceda y Allende, los detenidos desaparecidos, entre muchos otros hechos de la historia oficial traídos al baile, son las manifestaciones visibles de esta guerra en que Chile y sus habitantes no son más que herramientas, cuerpo y territorio, piezas quebradas o en mal funcionamiento, que conforman constructos tecnológicos, creados por poderes exteriores para sus propios fines siniestros.

En otros textos se sugieren algunas variantes, word in progress, de esta historia, por ejemplo, lo que se cuenta en "La conquista mágica de América", según lo cual Lucifer derrotado es lanzado al espacio y cae en el Polo, en donde permanece encadenado, con la cabeza eternamente torturada por el magma. La piedra azul de su diadema, Venus, se esconde en el cráneo de una machi, quien prevé la conquista europea.

Relacionado con lo anterior, un detalle de esta historia, sobre el cual Baradit siempre vuelve, es la estrella de la bandera, a partir de la cual construye el mito de Chile luciferino. Este, según es relatado en "La estrella solitaria y los símbolos luciferinos chilenos" de La historia secreta de Chile, explica que la estrella blanca de cinco puntas del pabellón nacional, puesta, no sobre el negro de la noche, sino sobre el azul que anuncia el amanecer, es Venus, 
el lucero de la mañana, y también Lucifer, nombre que viene de Lux Phoros, que significa "el que trae la luz". Apoyándose en la inscripción del primer escudo nacional -Post Tenebrax Lux - Baradit explica que los patriotas independentistas, aunque agnósticos y racionalistas, tenían conciencia de la necesidad de utilizar símbolos para difundir sus ideas: de ahí que hayan usado esa estrella que anuncia el fin del oscurantismo y el inicio de la edad de la luz y la razón. Lo anterior se relaciona con que Lucifer, en el gnosticismo, no es un ángel malvado, sino que es quien, en un mundo caído regido por un falso dios, trae el conocimiento a la humanidad. De ahí que la serpiente ofrezca a Adán y Eva una manzana, cuyas semillas, al partirla en dos, dejan ver una estrella de cinco puntas; la fruta del conocimiento, que es también obtenida por Venus en el mito griego de la manzana de oro de las Hespérides. A ello se suma la estrella mapuche, wuñelfe kushe, de ocho puntas que también representa al lucero y que, según se descubrió hace no mucho, está bordada debajo de la estrella de cinco puntas en la primera bandera nacional. De acuerdo a este mito, Chile es luciferino, es decir, el país, mirando hacia el amanecer de la cordillera, se orienta a la luz.

Antes del primer tomo de la Historia secreta, ya había aparecido una versión de este mito en Lluscuma, vinculado al escudo patrio y a la muerte de Allende:

Cuando los padres de la patria buscaron símbolos para inventar un país, eligieron al lucero que anuncia la llegada del Sol y escribieron Post Tenebras Lux bajo esa estrella, porque después de la oscuridad de la monarquía viene la luz de la razón, Venus, la estrella de la mañana que se llama Lucifer, Lux phoros, el que trae la luz. La estrella en la bandera de los mapuche era Venus también, la wunyelfe kushe, como estrella de ocho puntas. En la primera bandera chilena hay una estrella de cinco puntas pero en su interior, bordada con hilo blanco, hay otra estrella escondida, de ocho brazos; "la luz esotérica de la patria" [...]. Chile es luciferino. Allende quería cambiar la estrella de cinco esquinas por la luciferina de ocho, ipor eso lo mataron! [...]. Allende quería hacer el gesto mágico de cambiar el huemul por una serpiente en el escudo; habríamos tenido el símbolo del cielo y el de la tierra juntos. El cóndor es el norte, la serpiente es el sur, Cai cai vilú. $(211-212)^{11}$

11 En Synco la estrella de ocho puntas es el símbolo del proyecto informático. Un líder mapuche le explica el mito a Allende: "Compañero presidente, hoy la mapu está de fiesta, 
Otro episodio sobre el cual se ha construido el mito es el golpe militar, donde hay al menos dos ucronías: "El sueño de Contreras" de La guerra interior y Synco. En la primera, después de que un tal Manuel Contreras, de quien nada más se explica, sueña que al final de su vida es juzgado y encarcelado, las fuerzas armadas apoyan al presidente Allende y no ocurre el golpe. No obstante, el gobierno enfrenta una creciente sedición de parte de Estados Unidos, que lo lleva a buscar una alianza con la Unión Soviética que finalmente lo traiciona, todo lo cual termina con la invasión del país del norte. En tanto, en la novela de 2008, un acuerdo del gobierno de la Unidad Popular con la Democracia Cristiana, la derecha, los militares y Estados Unidos ha permitido que el golpe del 73 no ocurra y que se desarrolle una tecnología informática de avanzada, el proyecto Synco, en el que participan, entre otros Walter Rauff y Miguel Serrano, cuyo fin oculto es el retorno al pasado y el triunfo de los nazis, con la ayuda de Chile, en la segunda guerra mundial.

\section{EL TIEMPO Y LAS PALABRAS DEL MITO}

En el dispositivo que he descrito, el tiempo, concebido como un territorio que se recorre, se espacializa. Así, por él que se va y viene, traficando con fragmentos del pasado, los cuales puedes ser borrados, reimpresos, cambiados por completo, olvidados, recuperados. Esto es posible por la existencia de "soldados del tiempo" que intervienen constantemente la historia, lo que se explica en Lluscuma:

los peñis celebran la llegada de un avatar de Ngenechén con regocijo. Salvador no es sólo un nombre: usted es nuestro lonco, nuestro jefe, nuestra cabeza, el que nos cuida, el que nos salva. Usted es la estrella, el que nos guía. Los salvadores tienen su estrella de Belén para indicar el camino, la suya es la estrella roja como la sangre mapuche, de ocho puntas porque es un doble kultrún girando en el espacio. Cuatro más cuatro es ocho, número sagrado; la carta ocho del Tarot es La Justicia, el equilibrio, el buen juicio, el poder bien utilizado. La estrella de ocho puntas es Venus, nuestra wuñelfe kushe sagrada, la que aparece en nuestra bandera, el origen del pueblo mapuche y nuestro destino en este largo viaje de aprendizaje. Venus es el lucero, el que trae la luz, la primera luz que aparece en el cielo en la alborada de la raza. Usted es esa primera luz que despierta a nuestro pueblo y lo guía, compañero Presidente. Usted es nuestro Salvador con una estrella roja de ocho puntas en la frente" (187-188). En el cuento "Estrella de mañana" de La guerra interior hay una alusión a la relación de la estrella y la virgen en el nombre de la niña vidente monstruosa Estrella del Carmen. 
Los soldados del tiempo viajan a detener un atentado pero sus enemigos viajan antes a reforzarlo, entonces volvemos a viajar más atrás para prevenirlo y en esas maniobras chocamos contra todo, el barco aparece en lugares equivocados, hay que remendarlo todo, reparar los eventos [...]. El pasado está reescribiéndose y regrabándose constantemente en nuestras memorias, como quien corrige un archivo una y otra vez a medida que avanza, arrastrándose a dura penas por el lodo de la historia. Todo es saboteado por una memoria que se superpone. (222-23)

Así, el mito se construye a partir de la posibilidad de recorrer el tiempo, borrando y rehaciendo hechos, sobrescribiéndolo permanentemente, a lo que hay que agregar el poder mágico del lenguaje, que genera efectos materiales: "los tildes producen dolor en los oídos de algunos demonios, por eso el castellano es el mejor idioma para los exorcismos" (163), se explica en una parte de Lluscuma y en otra:

Las palabras son poderosas. Al interior de la Torah saben que una palabra puede terminar el mundo [...]. Hay frases compuestas de varias palabras poderosas que producen efectos mezclados, como moléculas de un producto químico tóxico [...], produciendo estados alterados, catatonia o coma. Un instituto hindú está manipulando frases de alta toxicidad como armas estratégicas en un laboratorio Ramadhji. Frases que matan. (209)

Palabras que intervienen en la configuración de lo real, que operan en los modos de entender lo que sucede como ocurre con las historias del autor de Ygdrasil.

\section{CONCLUSIÓN}

En la obra de Baradit la historia es un palimpsesto que se está construyendo todo el tiempo, a través de un dispositivo textual que procesa fragmentos de territorio, cuerpo y subjetividad, confundidos y mezclados, los que va conformando constructos tecnológicos que someten a los sujetos a poderes malignos superiores y los convierten en carne de cañón, esclava, de guerras que desconocen. La máquina opera en un tiempo lábil y modificable, que se concibe como un espacio factible de recorrer y de ser intervenido una y otra vez. Las palabras, poseedoras de un poder mágico, también integran este 
dispositivo, por su capacidad de afectar la realidad, en lo que puede verse la concepción del imaginario social como conformando los hechos y de la propia escritura que hace el autor de mitos de la Historia de Chile, o la que él ha llamado su "historia secreta", participando en la construcción de la memoria nacional y sumándose así a la disputa ideológica por la definición del pasado (Jelin 2002), que es también un modo de intervenir en la configuración del presente y el futuro.

\section{REFERENCIAS}

Areco, Macarena. "Imaginário baraditiano: Figurações do sujeito, da história e da tecnologia na obra de Jorge Baradit”. In: Jochen Volz, Gabi Ngcobo, Júlia Rebouças, Lars Bang Larsen e Sofía Olascoaga, eds. $32^{a}$ BIENAL DE SÃO PAULO - INCERTEZA VIVA. Dias de estúdio. São Paulo: Bienal de São Paulo, 2016, 196-205.

Baradit, Jorge. Ygdrasil. Buenos Aires: Ediciones B, 2005. . Lluscuma. Santiago: Ediciones B, 2013. . La guerra interior. Santiago: Penguin Random House, 2017. . Synco. Santiago: Penguin Random House, 2018.

Baczko, Bronislaw. 2005. Los imaginarios sociales. Memorias y esperanzas colectivas. Buenos Aires: Nueva Visión.

Brown, Andrew. Cyborgs in Latin America. New York: Palgrave Macmillan, 2010.

Castoriadis, Cornelius. 2007. La institución imaginaria de la sociedad. Buenos Aires: Tusquets.

Deleuze, Gilles y Felix Guattari. El Anti-Edipo: capitalismo y esquizofrenia. Barcelona: Paidos-Ibérica, 1998.

_. Mil mesetas. Capitalismo y esquizofrenia. Valencia, Pre-textos, 2015.

Gilbert, Sandra y Susan Gubar. La loca del desván: la escritora y la imaginación literaria del siglo XIX. Madrid: Cátedra, 1998.

Jelin, Elizabeth. Los trabajos de la memoria. Madrid: Siglo XXI, 2002. 
Haraway, Donna. Ciencia, cyborgs y mujeres La reinvención de la naturaleza. Madrid: Cátedra, 1995.

Le Breton, David. Antropología del cuerpo y la modernidad. Buenos Aires: Nueva Visión, 2002.

Ludmer, Josefina. Aqui América Latina: una especulación. Buenos Aires: Eterna Cadencia, 2010.

Montecino, Sonia. Mitos de Chile. Diccionario de seres, magias y encantos. Santiago: Sudamericana, 2003. 